\title{
Center Core Grants
}

National Cancer Institute

\section{Source}

National Cancer Institute. Center Core Grants. NCI Thesaurus. Code C20014.

Supports centralized resources and facilities shared by investig ators with existing funded research projects. The overall goal is to increase the effectiveness, capabilities, or productivity of current projects; to stimulate cooperative approaches; and/or to promote new research directions through multi-disciplinary or regional collaborations. 